\title{
narrativas do olhar
}

\section{(notas de um diário)}

\section{POR GABRIELA ROMEU}

Foi ouvindo histórias quando menina que adentrei o universo das infâncias, outras. As narrativas tecidas nas vozes de minha mãe e minhas tias me levaram a relatos afetuosos de suas peripécias infantis, as histórias que rondavam seu imaginário, as brincadeiras de pés descalços, os brinquedos costurados com restos do quintal, as encantarias para fazer e deixar crescer. Ouvir me levava a (vi)ver aquela infância. Foi então que fiz minha primeira incursão etnográfica pelas infâncias.

Meus olhos de leitora também tatearam outras infâncias. Incursionei pelos jeitos de ser menino e menina também pelas narrativas literárias, que sempre abrem portais de vastos mundos. Na prosa poética (e etnográfica) de Bartolomeu Campos de

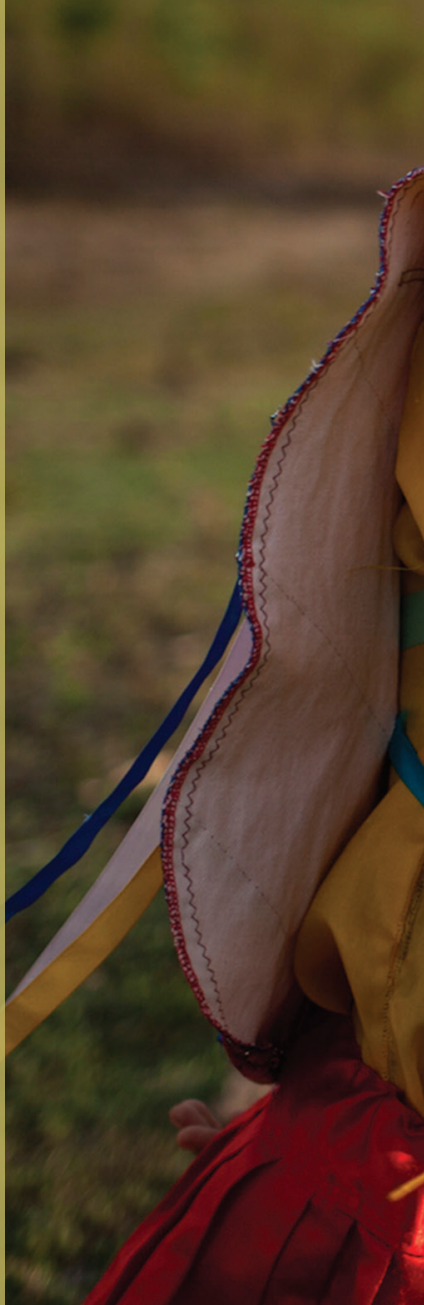


Queirós, descobri um atalho para a infância de um sertão onde meninos crescem silenciosos. 0 escritor mineiro, ao resgatar em sua obra suas memórias de criança, conta um pouco do viver a infância num certo tempo, num dado território.

\section{um certo Miguilim}

Vez ou outra volto a reler - ou (re)ver - Indez', em que o autor conta de forma poética como vinga o menino Antônio, nascido frágil, "fora do calendário", cuidado no protocolo de uma puericultura sertaneja, rica mitologia do crescimento. Antônio bebeu água do sino da igreja em dia de chuva para aprender a falar, uma "água do céu, sonora"; engoliu piaba para enfrentar as correntezas no nado; tinha como brinquedos os frutos caídos no chão e as mágicas da natureza; o lugar onde se enterrava o umbigo definia o destino da criança (se no curral, boiadeiro).

Um olho de vidro do avô materno era a relíquia escondida desse menino que "crescia manso". Aquele olho nunca dormia, espiava tudo - até os medos que vazavam das brechas da casa de adobe à noite. "Antônio imaginava o avô no céu, olhando Deus com um olho só. 0 outro não dormia nem mesmo na bolsa da mãe". A poética do olhar permeia a obra de Bartolomeu como a metáfora da descoberta de si e do outro - exercício fundamental de quem se dispõe a dialogar com as infâncias, a enxergar mais do que a "casca das coisas", assim como bem fazem as crianças.

Antônio é "um certo Miguilim”, menino nascido no Mutum, também lá das bandas das Gerais, criado na prosa lírica de um tal João Guimarães Rosa, escritor das veredas de um sertão grande. Há tempos sinônimo de criança, Miguilim simboliza a potência infantil em enxergar o avesso das coisas. Para adentrar o universo das infâncias, é sim essencial ter os olhos de Miguilim para escutar longe e espiar além, provocando deslocamentos e desestabilizando certezas. Emprestar das crianças lunetas, lentes e olhos da primeira vez.

\footnotetext{
1 QUEIRÓS, Bartolomeu Campos de. Indez. São Paulo: editora Global, 2004.
} 
Mas como olhar com esse olho da infância? Um outro escritor, Graciliano Ramos², nos indica outra trilha por meio dos causos narrados pelo personagem Alexandre. Resumindo bem, a história é assim: certa feita, Alexandre teve um entrevero com uma onça e perdeu um olho; procura que procura, ele encontrou o olho perdido, colocou-o de volta ao lugar, mas, para sua surpresa, acabou virado pra dentro e ali tudo espiava!

Então, descobri que esse olho virado pra dentro espia meu tempo de menina e todo o núcleo de infância que eu carrego persistentemente na bagagem do tempo. 0 outro olho espia a infância outra, os meninos e meninas que encontro pelos quintais Brasil afora. E assim, com um olho virado pra dentro e outro virado pra fora, surge um diálogo (ou uma troca olhares) entre infâncias.

\section{abridor de amanhecer}

Das incursões por infâncias que habitam memórias, já há quase duas décadas passei a incursionar por infâncias urbanas, ribeirinhas, quilombolas e indígenas, entre outras tantas, na minha prática como jornalista (e depois, como documentarista) dedicada ao registro dos cotidianos infantis em diferentes cantos do país.

Olhar, assim como escutar e dialogar, sempre foram um exercício. Com as crianças, não funcionam roteiros pré-definidos e as técnicas de entrevista não são nada eficazes. É preciso entrar no território da infância em estado de alerta. E também em estado de entrega: disponível ao encontro, num delicado, às vezes frágil, jogo dialógico.

Então emerge uma segunda pergunta: com quais ferramentas adentrar o universo das infâncias? Ao arrumar a bagagem para uma incursão pelas infâncias brasileiras, logo salta a poesia de Manoel de Barros: "Guarda num velho baú seus instrumentos de trabalho: um abridor de amanhecer; um prego que farfalha; um encolhedor de rios; um esticador de horizontes".

2 RAMOS, Graciliano. Histórias de Alexandre. Rio de Janeiro: editora Record, 2007.

3 BARROS, Manoel. O livro das ignorãças. Rio de Janeiro: editora Record, 2000. 
Mas, na bagagem, vai mesmo o básico: gravador, câmera fotográfica e caderneta. Com o tempo e outras práticas, a mala foi ganhando outros apetrechos: uma sacolinha com brincadeiras, um rolo de barbante, lápis de cor, canetinhas, papéis e um bom tênis para acompanhar as andanças dos miguilins - ou, mais recentemente, de cabinhas, como são chamadas as crianças no sertão do Cariri cearense. Mas nada disso serve se ferramentas imprescindíveis não estiverem afiadas: os olhos, a boca e os ouvidos - e, vá lá, braços e pés. É fundamental estar de corpo inteiro - mais a alma, é verdade - no encontro com as crianças.

\section{mulher-ouvido}

Recentemente, em palestra em passagem pelo Brasil, a escritora bielorrussa Svetlana Aleksiévitch, laureada com o Prêmio Nobel da Literatura, disse ser uma mulher-ouvido em seu ofício de recolher "sentimentos, pensamentos e palavras" cotidianas e invisíveis para seus livros, que trazem, por exemplo, relatos de adultos que enfrentaram a guerra quando crianças (Últimas testemunhas; tradução livre, ainda não publicado no Brasil). Ouvir é mais do que uma ferramenta no trabalho dessa escritora que há tempos tece habilidosamente romances a partir de uma polifonia de vozes, geralmente as esquecidas ou omitidas na história oficial.

Ouvir (ou auscultar, para extrapolar uma simples percepção auditiva), observar e dialogar são o ofício do pesquisador. Um pesquisador-ouvidos-profundos (para "escutar a cor do peixes"), também pesquisador-olhos-esticados (o tal "esticador de horizontes"), ainda um pesquisador-boca-miúda. É preciso estar em alerta para ouvir redobrado, enxergar alongado e falar o necessário (e saber quando não falar). "Nem tudo o que se vê é o que se vê; nem tudo que se ouve é o que se ouve", ouvi recentemente o palhaço Wellington Nogueira ${ }^{4}$ proferir num encontro cujo tema era a escuta das crianças.

\footnotetext{
4 SE ESTA RUA FOSSE MINHA - VAMOS OUVIR AS CRIANÇAS?, 2016, São Paulo.
} 
O antropólogo Vagner Gonçalves da Silva ${ }^{5}$, ao falar da entrada do etnógrafo em campo, ilustra essa chegada com um dos ritos de iniciação da cabula, modalidade de culto afro-brasileiro, em que “(...) o adepto deveria entrar no mato com uma vela apagada e voltar com ela acesa, sem ter levado meios para acendê-la (...)”. Além do exercício de olhar e escutar, é preciso saber iluminar aquilo que se vê e se ouve, criando seus próprios meios para tanto.

\section{ver é inventar}

Se o olhar é uma dessas potentes ferramentas, é fundamental também reconhecer a multiplicidade do visível. Ou seja, há muitas maneiras de ver e interpretar - acender a vela ou iluminar uma infância. A filósofa Viviane Mosé traça uma forte relação entre ver e imaginar: "Ver, portanto, é antes de tudo criar, na medida em que é reduzir, contornar; ver é inventar”. São tênues as linhas entre realidade e fantasia, assim como também versa o já citado poeta Manoel de Barros: "O olho vê, a lembrança revê, e a imaginação transvê. É preciso transver o mundo"6.

E foi numa busca em transver - ou inventariando (observando, reunindo, imaginando) - que mais recentemente adentrei o território dos cabinhas - ou a Terra de cabinha. De olhos bem abertos, percorri muitos terreiros em parceria com o fotógrafo Samuel Macedo, nascido na região e, portanto, com as lentes genuínas de um cabinha. Juntos, acompanhamos os cotidianos infantis, caminhamos pelo território para mapeá-lo afetivamente, conhecemos como é crescer naquele universo e também ouvimos as histórias, as sonoridades e as expressões da fala que permeiam aquela infância, num fluxo permanente entre o visível e o invisível, compondo um inventário de ser criança.

5 SILVA, Vagner Gonçalves da. O antropólogo e sua magia: trabalho de campo e texto etnográfico nas pesquisas etnográficas sobre religiões afro-brasileiras. São Paulo: Edusp, 2000, p. 9.

6 BARROS, Manoel de. Livro sobre nada. Rio de Janeiro: editora Record, 1997, p. 75.




Tal inventário foi sendo elaborado não apenas a partir do que se vê ou do que se ouve ou do que se fala. Mas a partir do que se vive, de corpo inteiro, junto às crianças. A criança é uma narradora de mundos e faz isso por meio de suas pequenas grandes aventuras cotidianas. “(...) a infância é caracterizada pela captura do mundo pela experiência e pela narração do mundo através de práticas. (...) O que se aprende através dos usos dos sentidos não pode ser ensinado através da oralidade. 0 pesquisador que almeja saber sobre as crianças deve apreender delas como elas apreendem do mundo: pela experiência"”.

\section{infanciografias}

Assim, no encontro com muitos cabinhas, vivemos as peripécias de caçar jumentos pelas capoeiras, seguimos pelas estradas a tradição dos caretas, rodamos pião depois da chuva, rascunhamos um glossário de expressões ensinadas pelos meninos maluvidos (ou malcriados, no dizer local), ouvimos histórias de um reino encantado nas pedras. Toda uma atmosfera que só foi possível recontar em imagens e em palavras porque dos meninos e meninas de lá emprestamos os olhos. Estava ali uma multiplicidade de olhares. Meus olhos virados, os olhos de um fotógrafo cabinha, olhos emprestados das crianças.

Sem nenhuma pretensão, mas numa tentativa de se delinear o próprio fazer, chamo esse olhar para as infâncias de um ensaio para alcançar etnografias literárias que partem do real - e recontam a realidade ${ }^{8}$. São uma espécie de infanciografias, ou escritas da infância, a partir da observação atenta das narrativas não-verbais das crianças, da escuta que faz ecoar mais do que o dito e do corpo acordado no encontro com a infância outra, num diálogo intenso com a meninice em que fui cunhada. Para falar das infâncias, as narrativas são muitas - e essa é só uma delas.

7 SOUSA, Emilene Leite de. As crianças e a etnografia: criatividade e imaginação na pesquisa de campo com crianças. Revista Iluminuras, Porto Alegre, v. 16, n. 38, p.140-164, jan./jul. 2015.

8 RECONTO DO REAL / COMKIDS NÃO FICÇÃO, 2016, São Paulo.

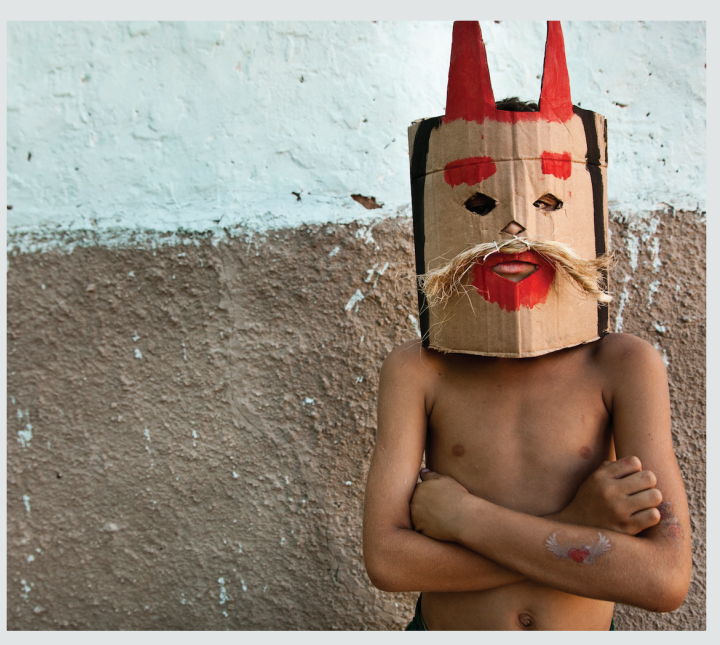

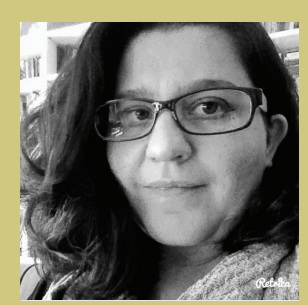

GABRIELA ROMEU

Jornalista e documentarista. Editou o caderno Folhinha, suplemento infantil do jornal Folha de S.Paulo, e coordenou o premiado projeto Mapa do Brincar. Em parceria com Marlene Peret, é idealizadora do Infâncias (www.projetoinfancias. com.br), que registra os cotidianos infantis pelo Brasil. É autora do livro Terra de cabinha (editora Peirópolis) e diretora do documentário Meninos e reis. É cocriadora do Mapa da Infância Brasileira (MIB). 


\section{TECENDO SABERES}

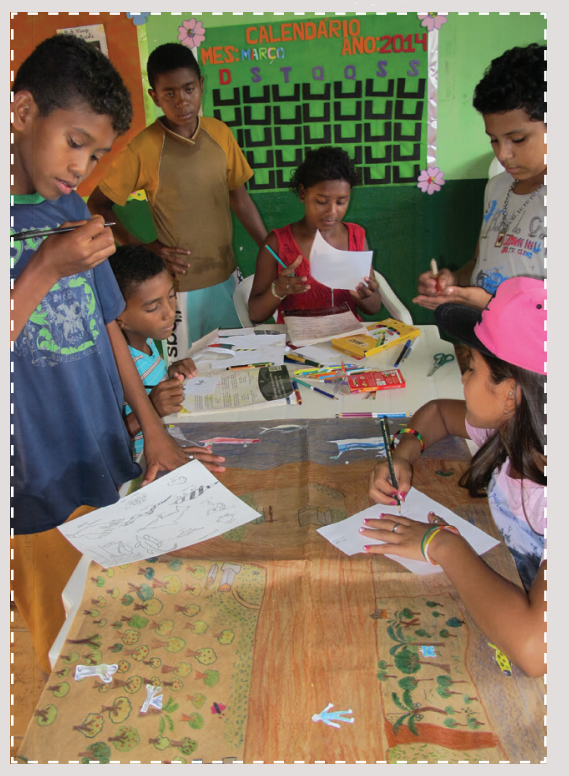

Descontruindo métodos pré-definidos, Marie Ange Bordas viaja para comunidades tradicionais para construir colaborativamente livros que retratam os saberes e fazeres das crianças, sempre mesclando arte, fotografia e escrita. A artista e escritora é a idealizadora do projeto Tecendo Saberes.

Em suas andanças pelo mundo, Marie Ange fala que se pauta pelo fluir da convivência, num processo orgânico, em que o papel principal da artista é instigar nas crianças um olhar mais ativo e observador sobre seu entorno, a partir de diversos processos criativos, como fotografar, desenhar e mapear os contextos. Assim nascem os projetos do Tecendo Saberes, como o Manual das Crianças Huni Kuĩ e o Manual das Crianças do Baixo Amazonas.

Segundo a autora, o mais importante do projeto é o fato de as crianças serem as protagonistas do levantamento e da escolha dos conteúdos do livro, resignificando e colocando em movimento o patrimônio cultural de suas comunidades a partir de seus olhares e sentidos.

Voltados para um público infantojuvenil, os livros têm uma estrutura de manual lúdico e científico que aborda os patrimônios material e imaterial, como língua, culinária, arte, lendas, brinquedos e brincadeiras. Com essas obras, Marie Ange espera que essas crianças quilombolas e indígenas entrem nas escolas e nas livrarias do Brasil pela "porta da frente", através de sua sabedoria e de sua cultura - e não apenas como objetos do estudo da diversidade brasileira.

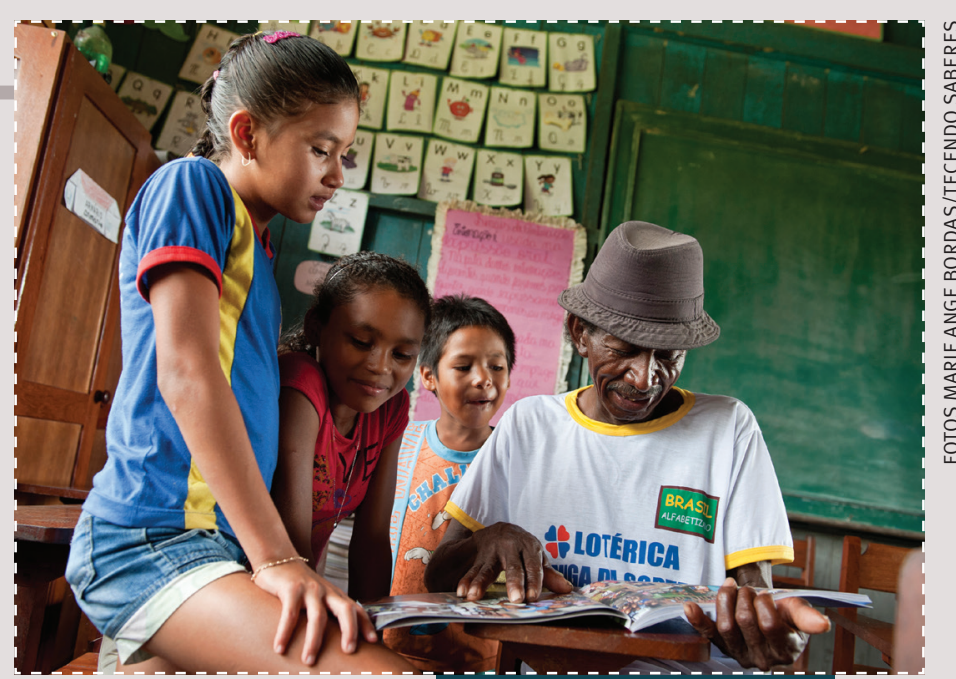

Infância caiçara

Crianças caiçaras andam pelo mato, catam fruta no pé, nadam no rio,

conhecem peixes e

sabem fazer farinha.

Esse cotidiano de meninos e meninas da comunidade da

Barra do Ribeira, no litoral da Jureia, está em textos e fotoilustrações do livro Manual da criança caiçara (editora Peirópolis), de Marie Ange Bordas. www.tecendosaberes. com 


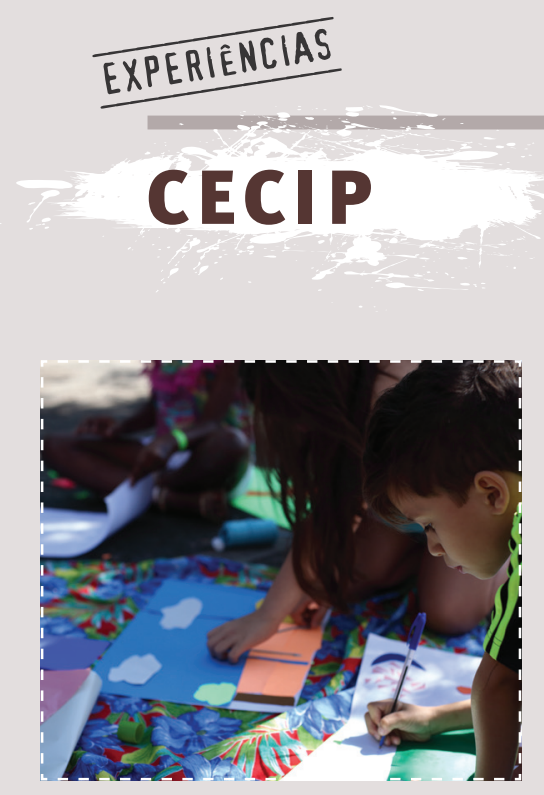

Inspirados por um grupo de pensadores como Paulo Freire, Eduardo Coutinho, Washington Novaes e Ana Maria Machado, o CECIP (Centro de Criação de Imagem Popular) foi criado para fortalecer, valorizar e divulgar práticas de participação infantil.

O CECIP foi criado no ano da eleição à Constituinte, 1986. A di-

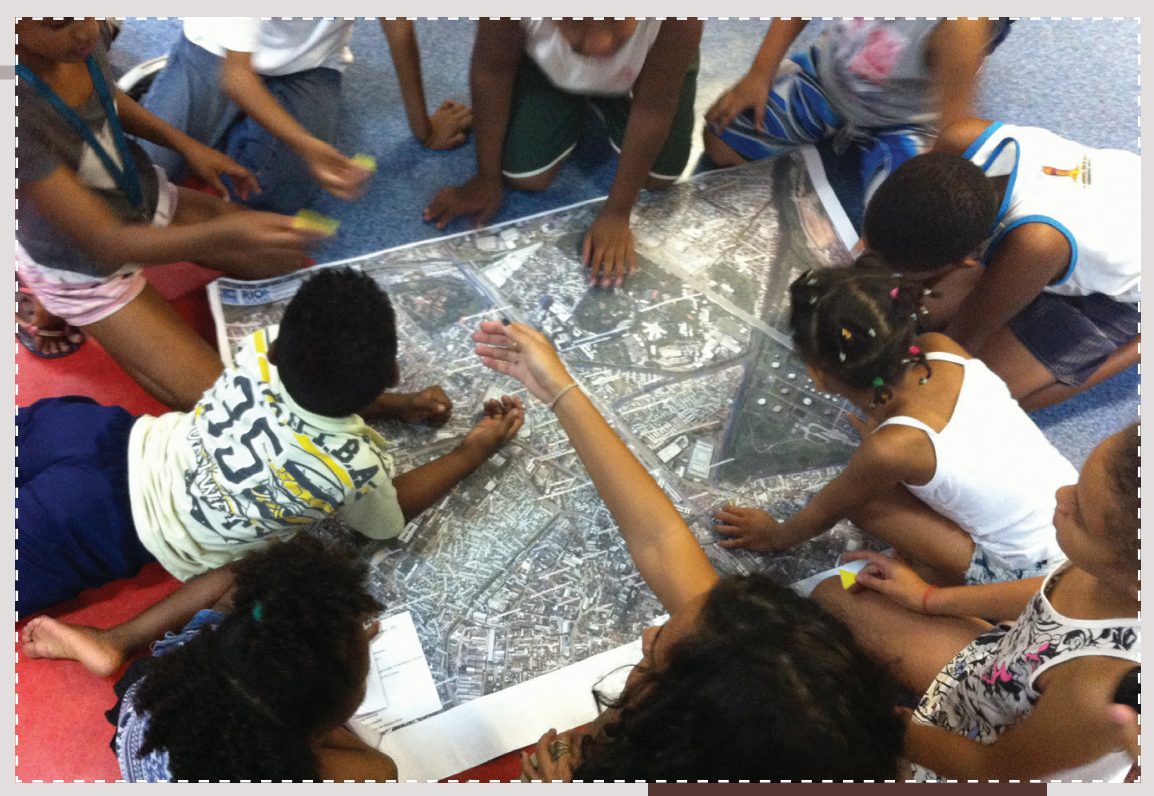
tadura apenas havia oficialmente acabado e o clima era de reconstrução democrática. A organização já nasceu com um viés metodológico forte da criança cidadã ou de um indivíduo que tem propriedade para intervir no mundo, assim como os adultos.

Com foco na autonomia que a criança tem para contribuir com a formação de uma sociedade democrática, o CECIP dá ênfase na atividade de educação, realizando uma série de campanhas sociais que influenciam políticas públicas de inclusão e proteção da infância. Criou projetos como o Criança Pequena em Foco, De Mãos Dadas e o Prêmio Nacional de Paticipação Infantil. Todos com fundamentos que combinam protagonismo e participação infantil.

Cruzando diversos morros cariocas com oficinas que tecem olhares lúdicos pela infância, a organização percebeu que a criança é capaz de olhar para a precariedade dos lugares ou moradias onde vivem transformando-os em espaços de afeto. E essas ações já surtem efeitos nas políticas públicas do município carioca. Para o CECIP, a criança se apropria do que está a sua volta, sente-se fortalecida e com isso sua auto-estima cresce.

Metodologia participativa Produzido pelo projeto Criança Pequena em Foco, do CECIP, a publicação Vamos ouvir as crianças? é um caderno de metodologias participativas que sugere atividades de trabalho. As atividades ajudam a dialogar com as crianças sobre os lugares onde moram, seus modos de vida e desafios cotidianos. www.cecip.org.br
口! .

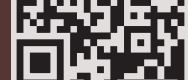

